\title{
A low-energy storage container for food and agriculture products
}

\author{
Francesco Barreca, Pasquale Praticò, Giuseppe Davide Cardinali \\ Department of Agriculture, Mediterranean University of Reggio Calabria, Reggio Calabria, Italy
}

\begin{abstract}
In 2018, the food, beverages, and tobacco sectors within the EU-27 consumed approximately 27,500 ktoe of energy. The food facilities and the food production plants are responsible for a large part of this energy consumption. Current global strategies focus on energy conservation and natural environmental protection, ascribing a lot of importance to building-related analyses. Areas for food storage are essential within the food production chain, as the indoor thermal parameters determine the characteristics of the final products. In this paper, a low-energy storage container is proposed. The envelope of the container is made from sandwich panels with a polyurethane layer paired with two phase change material (PCM) layers. The container is designed to store perishable materials, such as extra virgin olive oil. A storage container prototype, equipped with a mini-split heating, ventilation, and air conditioning electric system, was built to analyse and assess the energy spent during its use. Moreover, the achievable yearly energy savings with respect to a container without the PCM layers was calculated. The results showed that the PCM layers improve the energy performance of the container at an indoor temperature of $20^{\circ} \mathrm{C}$ with an energy saving of about $27 \%$, and at an indoor temperature of $17^{\circ} \mathrm{C}$ with an energy saving of over $22 \%$.
\end{abstract}

\section{Introduction}

In Europe, the building sector is responsible for about 39\% of energy consumption and produces over $30 \%$ of $\mathrm{CO}_{2}$ emissions; it is the biggest energy-consuming economic sector. The building sector includes a mix of residential and non-residential buildings,

Correspondence: Francesco Barreca, Department of Agriculture, Mediterranean University of Reggio Calabria, Reggio Calabria 89100, Italy.

Tel.: +39.096.51694215. E-mail: fbarreca@unirc.it

Key words: Agri-food; farm; phase change material; rural buildings; thermal energy.

Received for publication: 27 March 2021.

Accepted for publication: 10 June 2021.

CC Copyright: the Author(s), 2021

Licensee PAGEPress, Italy

Journal of Agricultural Engineering 2021; LII:1174

doi:10.4081/jae.2021.1174

This article is distributed under the terms of the Creative Commons Attribution Noncommercial License (by-nc 4.0) which permits any noncommercial use, distribution, and reproduction in any medium, provided the original author(s) and source are credited. where industrial buildings are a large part of the second group. According to Eurostat (2021), in 2018, the food, beverages, and tobacco sectors within the European Union (EU) consumed approximately 27,500 ktoe of energy. A large part of it (over $75 \%$ ) was used for food processing, distribution, preparation, and cooking (Sims et al., 2016; Ladha-Sabur et al., 2019). Environment control in food facilities and food buildings is responsible for a large part of this energy consumption. Current global strategies focus on energy conservation and natural environmental protection, ascribing a lot of importance to building-related analyses. In fact, in recent years, the EU issued a large number of directives and regulations, such as the European Green Deal (European Commission, 2019), which aim to improve energy efficiency and reduce greenhouse emissions to curb fossil fuel consumption by 2050. Reducing energy consumption in buildings has now become a critical challenge. Building retrofitting activities focus mainly on improving the thermal insulation of external walls. At same time, the building envelope plays an important role in energy savings, as it has to limit thermal loss. The amount of energy required for heating and cooling buildings is primarily determined by the thermal parameters of the external walls, which account for $25-30 \%$ of the total energy loss in buildings (Di Perna et al., 2011; Basinska et al., 2021).

Therefore, there is an urgent need to improve the thermal performance of external walls by thermal insulation in order to improve energy performance of buildings and increase energy efficiency (Barbaresi et al., 2020b). There are various solutions available for building thermal passive control, however the most traditional one is the use of high thermal insulation materials together with a high thermal capacity of the building envelope (Barbaresi et al., 2020a). In fact, thermal insulation limits heat loss, whereas thermal capacity improves the thermal inertia of the envelope, taking advantage of the external thermal daily cycle (Rosso et al., 2021).

Over last years, building technologies have proposed innovative green solutions consisting of green materials such as cork, hemp fibres, wool, cellulose fibres, and other high thermal performance synthetic materials, which all have a low thermal capacity (Barreca and Fichera, 2016; Parlato and Porto, 2020). To cope with this problem, new types of materials have been developed based on the capacity to absorb or release heat, when the material changes its phase from solid to liquid and vice versa or when the internal structure of the material changes. These materials are named phase change materials (PCM) (Osterman et al., 2012). There are three main substances that release/absorb sufficient energy during a phase transition: i) organic (carbon-containing) materials derived from petroleum, plants, or animals; ii) inorganic materials such as salt hydrates, which generally use natural salts; and iii) eutectic mixtures with a solid-to-solid phase change (Boussaba et al., 2018).

When the PCM is solid and the environmental temperature is close to the melting temperature, the incoming energy starts a melting process. When the temperature decreases, the PCM solidifies and returns the heat to the environment (Caprara and Stoppiello, 2012). These two stages are called 'load' and 'unload'. 
In theory, this cycle could continue forever, but, in fact, the PCM has a range of melting/freezing cycles from 100 to 10,000 (Gao et al., 2013) (Talašová and Holeček, 2009), which depend on the type of PCM substance (Sutterlin, 2015).

The phase change of the PCM occurs at a constant temperature, and therefore, it promotes the stabilization of the environmental indoor temperature, however it is very important to choose the correct melting temperature in relation to the target indoor temperature range (Alawadhi, 2008; Castell et al., 2009; Osterman et al., 2012; Buonomano et al., 2016).

In particular, food buildings and food storage areas need a controlled temperature within the correct range to guarantee good food product preservation conditions. Additionally, heating, ventilation, and air conditioning (HVAC) systems are usually an inherent part of food storage areas (Pérez-Lombard et al., 2011). Therefore, the significant interest in identifying ways to improve energy efficiency in food buildings is due to their high energy saving potential.

A food storage area is essential for the food production chain, as the inside environment influences the quality, the taste, the health, and the nutritional characteristics of the final products. In particular, the environmental temperature and humidity affect microbial development, hygiene and safety of the stored food (Barreca and Praticò, 2018).

The food quality starts from the field, and it is equally important to store the raw material in an adequate manner at the correct temperature to prevent deterioration and poor-quality food.

Around $19 \%$ of the total food wasted in the EU is estimated to come from the processing stage, making it the second largest contributor to food waste. Known drivers of food waste at the processing stage include inadequate control systems, inefficient operations, poor use of equipment, spoilage caused by suboptimal handling and storing conditions, damage incurred during transportation, and cold chain inefficiencies (Canali et al., 2017).

Farms or small agri-food companies often have to equip themselves with specific storage areas for a short time; therefore, having a temporary facility could be a suitable solution (Porto et al., 2017). In this study, we proposed an innovative portable container, with a sandwich envelope structure and two PCM layers paired with a conventional polyurethane sandwich panel to store perishable goods, such as food or agricultural raw materials. In particular, a prototype equipped with a mini-split HVAC electric system was made to contain extra virgin olive oil (EVOO) (Barreca and Praticò, 2019) in optimal thermal environmental conditions (Tinti et al., 2015). This prototype was monitored and analysed during use. At the end, we calculated the achievable yearly energy saving of this innovative container.

\section{Materials and methods}

This innovative portable container was conceived for temporary storage of EVOO bottles and cans and was kept outside an olive oil company in Rizziconi, a small town in southern Italy. Generally, the best conditions for storing EVOO for a long period of time are a dark environment with a temperature in the range of $8-22^{\circ} \mathrm{C}$ with low humidity and no direct sunlight. These environmental conditions delay the decline of polyphenols and the loss of the nutritional and taste qualities of this important and valuable food product. For this reason, a specific storage container was designed with a size of about $14 \mathrm{~m}^{2}$, a rectangular shape of about $2.50 \times 6.00 \mathrm{~m}$, and an internal height of $2.4 \mathrm{~m}$ (ISO container measure) (Figure 1).

Temperature control is guaranteed by means of a $1.25 \mathrm{~kW}$ HVAC mini electric split with an inverter system. It was chosen to conceive a specific sandwich panel with two PCM layers joined to a polyurethane foam panel for the container envelope. The application of the PCM to only one side of the envelope is widely used in residential buildings and performs well as it ensures a high thermal inertia. In this paper, we analysed an innovative sandwich panel with two PCM layers, one on the inside and on the outside of the envelope. The external PCM layer was applied to absorb outdoor daytime heat and release it when the temperature cools down during the night. The internal PCM layer was applied to absorb and release heat to maintain a constant temperature around $20^{\circ} \mathrm{C}$, which is a temperature value largely adopted by local olive oil producers.

The analysis and sizing of the sandwich panels were conducted by 'PCM express' (developed by Dr. Valentin Energie Software $\mathrm{GmbH}$ ), a planning and simulation software for the use of PCM materials (Gourlis and Kovacic, 2016).

This prototype was monitored and analysed during use. Subsequently, we calculated the achievable annual energy savings of this innovative container.

\section{Thermal simulation and design of the container}

The most important characteristic of PCMs are latent heat and temperature at fusion. In fact, the PCM is activated (absorbs or releases heat) only when it reaches the phase change characteristic temperature. Therefore, it is advisable to choose and maintain the correct transition temperature depending on the temperature of the indoor environment (Özonur et al., 2006). The design process requires a dynamic thermal model that takes into consideration the external heat flux and the PCM latent heat curve (Barbaresi et al., 2014). For the specific EVOO storage container, an analysis was conducted on the possible combinations among three PCM layers of the product by INSOLCORP ${ }^{\odot}$ with different transition temperatures, i.e., 18,21 , and $25^{\circ} \mathrm{C}$. These temperature values were chosen because they were the values closest to the reference temperatures on the market. The PCM software is a commercial software based on a finite difference mathematical method to simulate PCM behaviour. For the analysis, an indoor temperature value of $20^{\circ} \mathrm{C}$, constant in winter and summer, and an electric HVAC with a maximum cooling output of $100 \mathrm{~W} \cdot \mathrm{m}^{-2}$ were considered. The International Weather for Energy Calculations file (IWEC 164200) was used to calculate the external temperature. A simulation was carried out by means of PCM express for each layered combination to calculate the yearly energy spent to maintain a constant temperature of $20^{\circ} \mathrm{C}$ inside the container. The thermal characteristics of the different layers of the container envelope are reported in Table 1. The panels with PCM21+Pu+PCM25 layers and with $\mathrm{PCM} 21+\mathrm{Pu}+\mathrm{PCM} 21$ proved to be the best solutions. For both, the amount of energy used per annum was around $1160 \mathrm{~kW} \mathrm{~h}$. The first

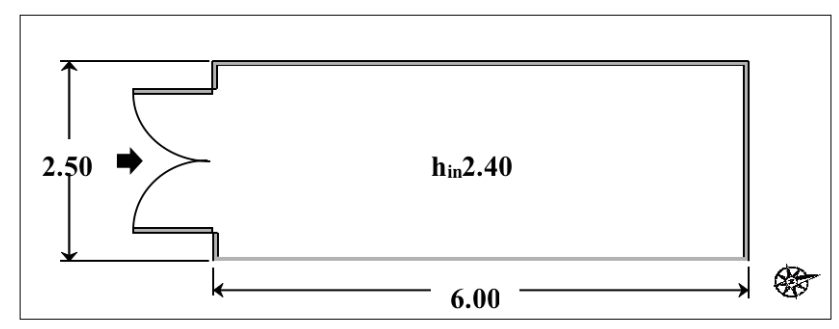

Figure 1. Layout of the low-energy storage container designed for food and agricultural products. 
solution $(1158.91 \mathrm{~kW} \mathrm{~h})$ is slightly lower than the second. The one with the lowest consumption was chosen (Table 2).

\section{Prototype monitoring}

The container prototype with a building envelope made of three layers (PCM 21+Pu+PCM 25) (Figure 2B) was built and positioned on free land and exposed to weather conditions (Lat. $38.40^{\circ} \mathrm{N}$; Long. $15.95^{\circ}$ E.).

It was equipped with a $1.25 \mathrm{~kW}$ HVAC split system, with an energy efficiency ratio equal to 2.81 , a coefficient of performance in heating $(\mathrm{COPh})$ equal to 3.95 , and a coefficient of performance in cooling (COPc) equal to 2.84 (Figure 3 ). The weather parameters of the site were surveyed by means of a first class Piranometer (LSI-LASTEM DPA 154 model) for solar irradiance measurement, a thermohygrometer completed with a natural ventilation anti-radiant shield (LSI-LASTEM DMA 672 model) for measuring air temperature and relative humidity. The inside thermal parameters were measured by means of a net of sensors linked to a data logger that recorded the thermal parameters every $15 \mathrm{~min}$. The indoor net was composed of a Psychrometer sensor with wet and dry bulbs and forced ventilation to measure the inside air temperature. Two plate sensors, one heat flow meter to measure the envelope surface temperature, and one heat flow meter to measure the heat flow that crossed the envelope were used. An energy cost measuring device (Voltcraft Energy Logger 4000) that recorded data every 15 min was connected directly to the electric grid to monitor the energy usage by the HVAC system.

The prototype was monitored from 01.08.2020 to 30.11.2020. The monitoring period was divided into two phases, the first was from 01.08.2020 to 30.09.2020 and the second was from 01.10 .2020 to 30.11 .2020 . The indoor temperature was maintained at round $20^{\circ} \mathrm{C}$ during the first period. To test the pro-

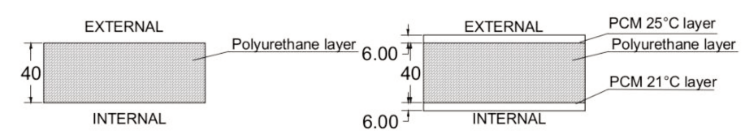

Figure 2. The Pu layer (A) and phase change material (PCM) 25Pu-PCM 21 sandwich panels (B) of the building envelope.

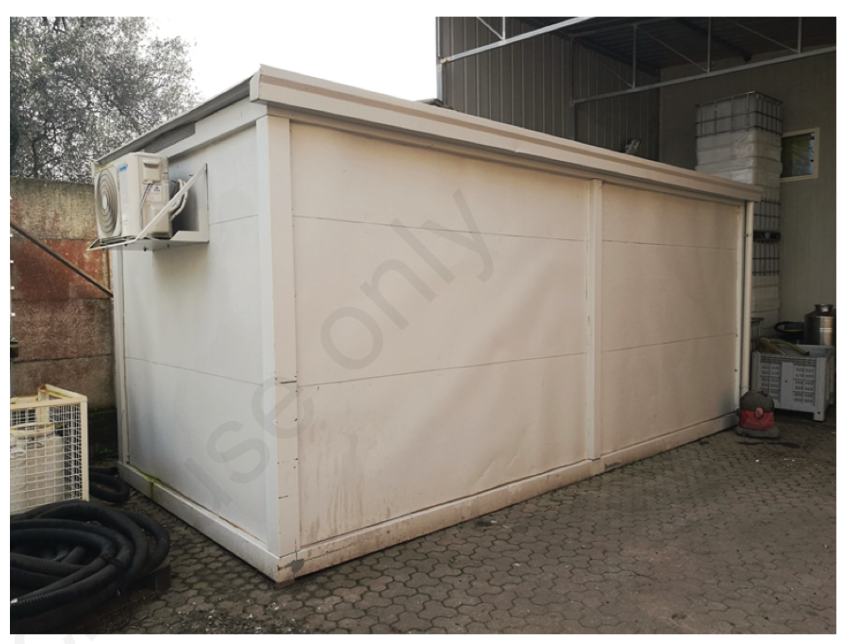

Figure 3. Prototype monitoring.

Table 1. The thermal characteristics of sandwich panel layers.

\begin{tabular}{|c|c|c|c|c|c|c|c|}
\hline Materials & $\begin{array}{l}\text { Thickness } \\
\text { (mm) }\end{array}$ & $\begin{array}{l}\text { Density } \\
\left(\mathrm{kg} \cdot \mathrm{m}^{-3}\right)\end{array}$ & $\begin{array}{l}\text { Specific heat capacity } \\
\left(\mathrm{kJ} \cdot \mathrm{kg}^{-1} \cdot \mathrm{K}^{-1}\right)\end{array}$ & $\begin{array}{l}\text { Thermal conductivity } \\
\qquad\left(\mathrm{W} \cdot \mathrm{m}^{-1} \cdot \mathrm{K}^{-1}\right)\end{array}$ & $\begin{array}{l}\text { Resistance } \\
\left(m^{2} \cdot K \cdot W^{-1}\right)\end{array}$ & $\begin{array}{l}\text { Melt point } \\
\text { temperature } \\
\left({ }^{\circ} \mathrm{C}\right)\end{array}$ & $\begin{array}{l}\text { Latent heat } \\
\left(\mathrm{kJ}^{\mathrm{kg}} \mathrm{kg}^{-1}\right)\end{array}$ \\
\hline Polyurethane core & 40 & 35.00 & 1.59 & 0.02 & 1.82 & & \\
\hline $\mathrm{PCM} 25^{\circ} \mathrm{C}$ & 6 & 900.00 & 3.14 & $\begin{array}{l}0.54 \text { (liquid phase) } \\
1.09 \text { (solid phase) }\end{array}$ & $\begin{array}{l}0.0111 \text { (liquid phase) } \\
-0.0055 \text { (solid phase) }\end{array}$ & 25 & 2.32 \\
\hline $\operatorname{PCM} 21^{\circ} \mathrm{C}$ & 6 & 900.00 & 3.14 & $\begin{array}{l}0.54 \text { (liquid phase) } \\
1.09 \text { (solid phase) }\end{array}$ & $\begin{array}{l}0.0111 \text { (liquid phase) } \\
0.0055 \text { (solid phase) }\end{array}$ & 21 & 2.32 \\
\hline $\operatorname{PCM} 18^{\circ} \mathrm{C}$ & 6 & 900.00 & 3.14 & $\begin{array}{l}0.54 \text { (liquid phase) } \\
1.09 \text { (solid phase) }\end{array}$ & $\begin{array}{c}0.0111 \text { (liquid phase) } \\
0.0055 \text { (solid phase) }\end{array}$ & 18 & 2.32 \\
\hline
\end{tabular}

Table 2. Energy consumption for different sandwich panel layer combinations (internal, intermediate, and external).

\begin{tabular}{|c|c|c|c|c|c|c|}
\hline In & Sandwic & ayer par & $\begin{array}{l}\text { nperature } \\
\left({ }^{\circ} \mathrm{C}\right)\end{array}$ & $\begin{array}{l}\text { Heating energy } \\
\text { consumption } \\
\text { (kW.h) }\end{array}$ & $\begin{array}{l}\text { Cooling energy } \\
\text { consumption } \\
\text { (kW·h) }\end{array}$ & $\begin{array}{c}\text { Yearly energy } \\
\text { consumption } \\
(\mathrm{kW} \cdot \mathrm{h})\end{array}$ \\
\hline & $\mathrm{Pu}$ & & 20 & 782.59 & 988.74 & 1771.33 \\
\hline PCM18 & $\mathrm{Pu}$ & PCM21 & 20 & 435.76 & 916.35 & 1352.11 \\
\hline PCM18 & $\mathrm{Pu}$ & PCM25 & 20 & 566.69 & 907.40 & 1474.09 \\
\hline PCM18 & $\mathrm{Pu}$ & PCM18 & 20 & 311.31 & 921.85 & 1233.66 \\
\hline PCM21 & $\mathrm{Pu}$ & PCM25 & 20 & 254.96 & 903.95 & 1158.91 \\
\hline PCM21 & $\mathrm{Pu}$ & PCM21 & 20 & 259.85 & 903.84 & 1163.69 \\
\hline PCM25 & $\mathrm{Pu}$ & PCM25 & 20 & 324.01 & 936.81 & 1260.82 \\
\hline
\end{tabular}

In, internal; M, intermediate; Ex, external; PCM, phase change material. 
totype at different temperatures, the indoor temperature was maintained around $17^{\circ} \mathrm{C}$ during the second period.

For each month during the monitoring period the average daily trend of the global sun radiation, and the indoor and outdoor air temperature were calculated using Equation (1). These thermal parameters described the conditions of a monthly 'generic day' (Figure 4).

$\boldsymbol{G}\left(t_{i}\right)=\frac{\sum_{k=1}^{n} G^{k}\left(t_{i}\right)}{n}$

where:

$\boldsymbol{G}\left(t_{i}\right)$ is the mean value of the parameter $G$ at a generic time $t_{i}$ for the 'type of day',

$G^{k}\left(t_{i}\right)$ is the value of the parameter $G$ at a generic time $t_{i}$ of day $k$, and

$n$ is the number of the monitored days during the period.
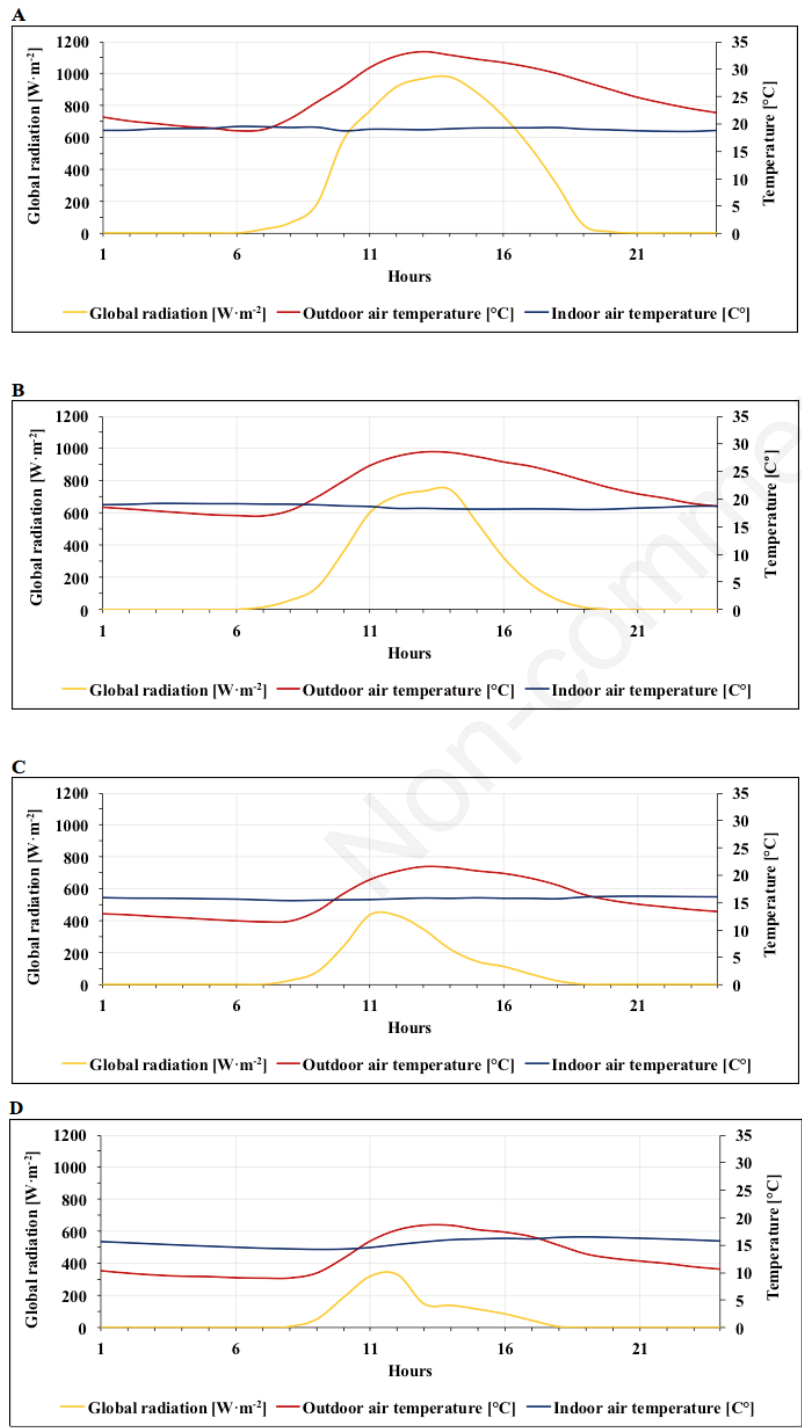

Figure 4. The global radiation, and indoor and outdoor air temperature of a generic day in August (A), September (B), October (C), and November (D).

\section{Results and discussion}

August was the hottest month during the experimental period. The external weather sensors detected a maximum sun radiation of about $1200 \mathrm{~W} \cdot \mathrm{m}^{-2}$ and a maximum air temperature of $32^{\circ} \mathrm{C}$.

For this month, the daily mean heat flux was below $4 \mathrm{~W} \cdot \mathrm{K}^{-}$ ${ }^{1} \cdot \mathrm{m}^{-2}$ until 2:00 pm and was followed by an increasing trend until 6:15 p.m., up to $7.17 \mathrm{~W} \cdot \mathrm{K}^{-1} \cdot \mathrm{m}^{-2}$, and a decreasing trend below 4 $\mathrm{W} \cdot \mathrm{K}^{-1} \cdot \mathrm{m}^{-2}$ until $11: 15 \mathrm{pm}$.

The daily sun radiation reached a peak of $1.028 \mathrm{~W} \cdot \mathrm{m}^{-2}$ at $1: 15$ pm when, at the same time, the daily outdoor air temperature reached a max value of $33.24^{\circ} \mathrm{C}$.

The average daily temperature in August highlighted a temporal phase shift of about 5 hours between the daily sun radiation trend and the daily heat flux trend (Figure 5).

This temporal phase shift was determined using the external layer of $\mathrm{PCM}$ which, at a temperature of $25^{\circ} \mathrm{C}$, started to melt and to absorb the heat and delayed the incoming heat flow. When the temperature decreased, the PCM solidified and released latent heat into the environment (Figure 6).

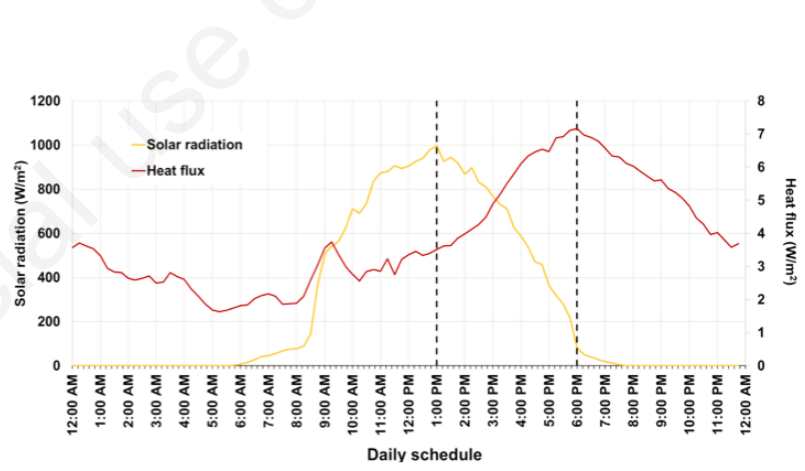

Figure 5 . The mean daily global radiation and mean daily heat flux in August.

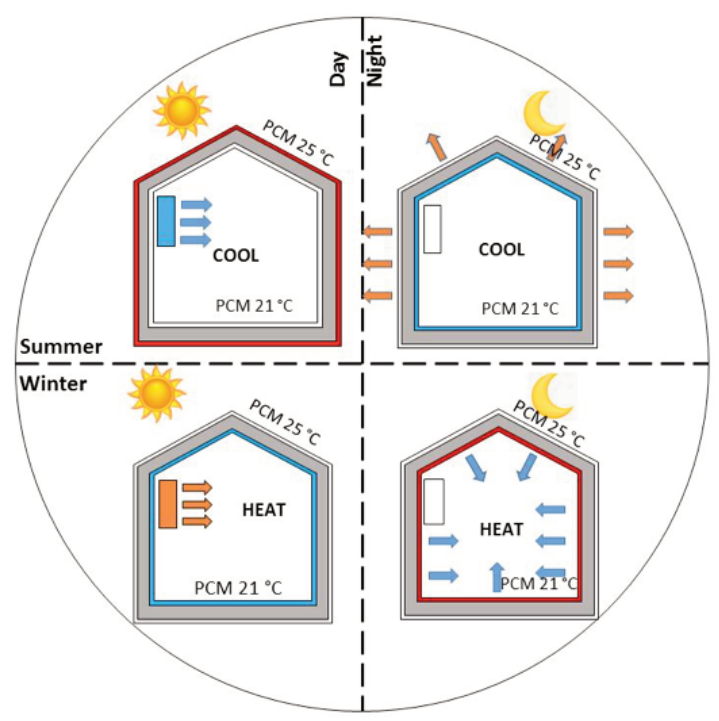

Figure 6. Operating principle of the container during the seasons. PCM, phase change material. 
The monthly energy used by the HVAC split system to condition the temperature of the indoor environment and to maintain a constant temperature of $20^{\circ} \mathrm{C}$ for the first monitoring period is reported in Table 3. The maximum energy measured was about $6.18 \mathrm{kWh}$ on $20^{\text {th }}$ August, while the total consumption during the period was $221.06 \mathrm{kWh}$

During the second monitoring period, the daily energy used by the HVAC split system was measured to condition the temperature of the indoor environment and to maintain a constant temperature of $17^{\circ} \mathrm{C}$ to evaluate the performance of the prototype with a different design temperature.

The max monthly energy measured was $45.71 \mathrm{kWh}$ in October, and the total measured energy consumption was around $63.05 \mathrm{kWh}$ (Table 4).

The prototype was modelled by means of the DesignBuilder software. DesignBuilder is an Energy Plus-based software tool used for energy measurement in buildings and is a transient heat conduction solver (Jaffal and Inard, 2017). The calculation was carried out with the finite-difference method. For the accuracy of the model, it is important to define the envelope thermal material parameter values such as thickness, density, specific heat capacity, thermal conductivity, resistance, and melting point temperature of the PCM (Table 1) (Barreca et al., 2017). In particular, it is important to define the correct function of the temperature enthalpy for the PCM (Figure 7), which is adopted in the energy model, because it is specific for each PCM product (Zastawna-Rumin et al., 2020). The producer of the PCM has to release this data, because they are very important for the numerical simulation.

The accuracy of the energy analysis is also correlated with the meteorological data set precision. A thermal analysis simulation was conducted with reference to the climate parameters surveyed on site during the first monitoring period. The electric energy consumption was estimated by the analysis simulation to control the indoor air temperature at around $20^{\circ} \mathrm{C}$.

These results were compared with the real energy consumption values that were measured during the first monitoring period (Figure 8). A comparison between the measured values and the calculated values confirmed the reliability of the prototype energy model. In the ASHRAE guidelines 14 (Haberl et al., 2005), two statistical indices are used to determine the compliance of the simulation model and the uncertainty of the analysis. The first is the mean bias error (MBE), which is found by first calculating the difference between measured energy consumption and simulated

Table 3. Energy consumption measured to maintain an indoor temperature of $20^{\circ} \mathrm{C}$ with an envelope composition with layers of PCM21+Pu+PCM25.

\begin{tabular}{cc} 
First monitoring period & Energy [kWh] \\
\hline August & 136.87 \\
September & 80.56 \\
\hline Total & 217.43 \\
\hline
\end{tabular}

Table 4. Energy consumed to maintain a temperature of $17^{\circ} \mathrm{C}$ inside the prototype with an envelope layer composition of PCM21+Pu+PCM25.

\section{First monitoring period}

October Bnergy [kWh]

\begin{tabular}{cc} 
October & 45.71 \\
November & 17.34 \\
\hline Total & 63.05 \\
\hline
\end{tabular}

energy consumption for a given time period. The differences are then summed up and divided by the sum of the measured energy use over the same time period. The second statistical index, which indicates the uncertainty of the model results, is the coefficient of variation of the root mean squared error CV(RMSE).

$G^{k}$

$M B E=\frac{\sum_{i=1}^{n}\left(m_{i}-s_{i}\right)}{\sum_{i=1}^{n}\left(m_{i}\right)}$

where

$m_{i}$ is the measured value,

$s_{i}$ is the simulated value, and

$n$ is the number of measure data points.

$C V(R M S E)=\frac{1}{\bar{m}} \sqrt{\frac{\sum_{i=1}^{n}\left(m_{i}-s_{i}\right)^{2}}{n}} \times 100(\%)$

where

$m_{i}$ is the measured value,

$s_{i}$ is the simulated value,

$n$ is the number of measure data points, and

$\bar{m}$ is the mean of measured values.

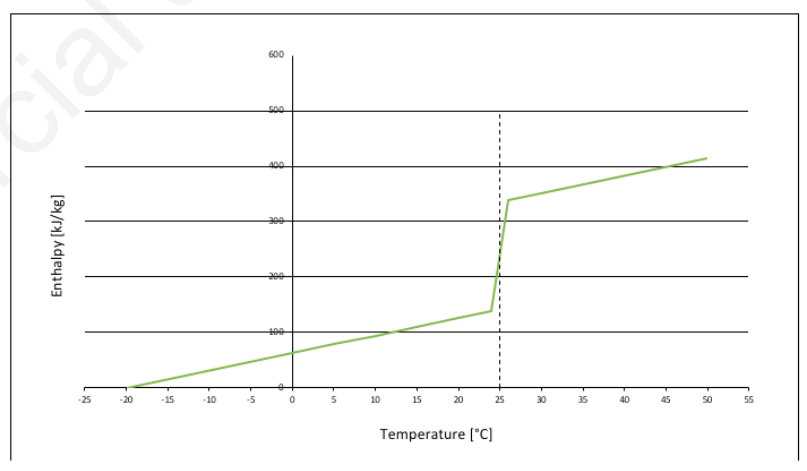

Figure 7 . The enthalpy curve of phase change material at $25^{\circ} \mathrm{C}$.

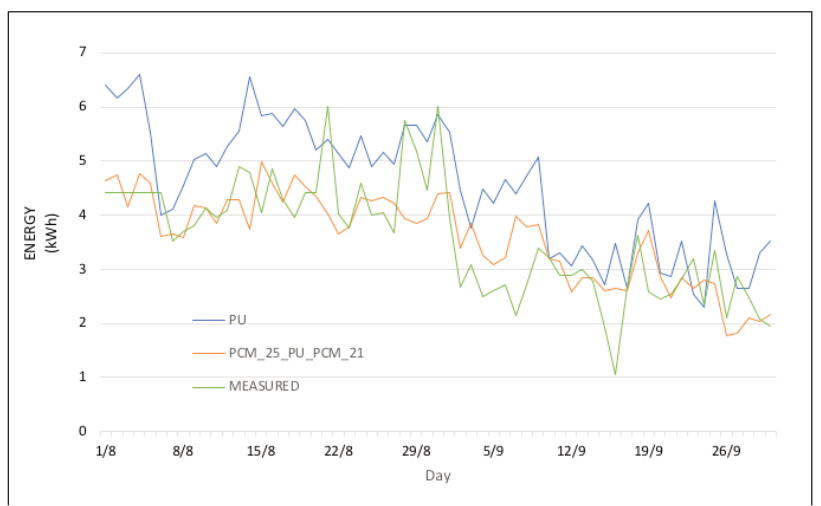

Figure 8. A comparison between the measured and estimated electric usage for a container with a single Pu layer and phase change material (PCM) 25-Pu-PCM 21 sandwich panels during the first monitoring period. 
The CV(RMSE) is calculated by dividing the root mean squared error by the measured mean of the data. $\mathrm{MBE}=0.70 \%$ and $\mathrm{CV}(\mathrm{RMSE})=14.34 \%$ were obtained for the case study. TModels are declared to be calibrated if they produce MBEs within $\pm 5 \%$ and CV(RMSE)s within $\pm 15 \%$ when using monthly data (Gourlis and Kovacic, 2016; Ruiz and Bandera, 2017). The compliance of the prototype simulation model allowed us to assess the thermal performance of the low-energy storage container proposed. The prototype model was modified to calculate the energy used without the PCM layers of the envelope sandwich panels. For this purpose, the walls of the container were made only with polyurethane. An energy analysis was conducted for the first monitoring period to maintain a temperature of $20^{\circ} \mathrm{C}$. The result was an electric energy consumption of over $277 \mathrm{kWh}$ (about $27 \%$ plus) compared to the monitored prototype (Table 5).

The same energy model was also considered for the second monitoring period; it allowed us to calculate the energy consumed in this period to maintain a temperature of $17^{\circ} \mathrm{C}$.

An energy simulation was also performed for the second monitoring period. The values of $\mathrm{MBE}=-0.03 \%$ and $\mathrm{CV}(\mathrm{RMSE})=7.26 \%$ were obtained. These statistical indices confirmed the model reliability, and allowed us to carry out other energy simulations. In particular, a specific simulation was carried out to assess the thermal performance of the storage container at $17^{\circ} \mathrm{C}$ without the two PCM layers matched to the envelope layers. The energy calculated for the storage container without PCM was $48.73 \mathrm{kWh}$ (lower by $22.72 \%$ ) compared to the energy used by the prototype $(63.05 \mathrm{kWh})$ to maintain a temperature of $17^{\circ} \mathrm{C}$ (Figure 9 ). A comparison of the energy consumed by the container prototype and the same container without the PCM layers (Figure 6), maintaining a temperature of around $20^{\circ} \mathrm{C}$ from August to September, led to energy savings of about $59.64 \mathrm{kWh}$, over $27 \%$ of the total energy spent. The same analysis conducted for the months

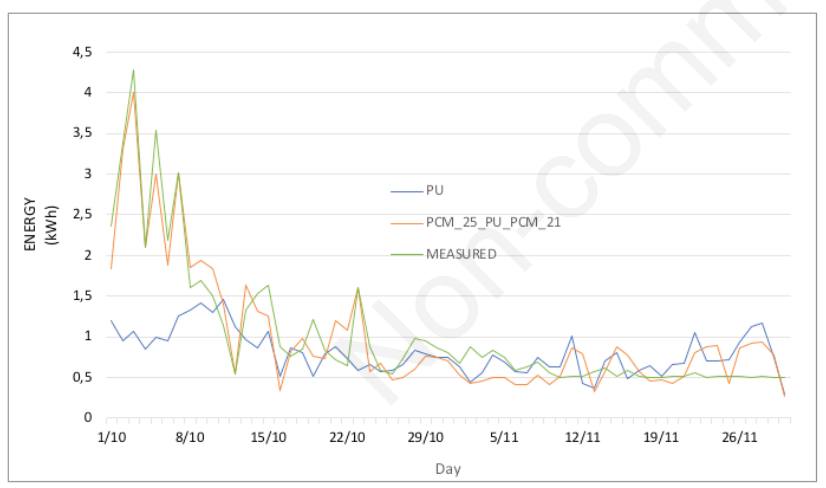

Figure 9. A comparison between the measured prototype energy and estimated energy usage by a container with a single Pu layer and phase change material (PCM) sandwich panels during the second monitoring period. of October and November, but maintaining a temperature of $17^{\circ} \mathrm{C}$, showed a higher energy usage $(+23 \%)$ for the prototype monitored compared to the energy model without the two PCM Layers. During this period, the HVAC used electric energy to heat the indoor environment, because the external mean daily air temperature was lower than the indoor temperature for several hours (Figure 4C and D). It is important to note that the choice of the two PCM layers was made with specific reference to a constant temperature of $20^{\circ} \mathrm{C}$. A different temperature range used caused a system malfunction and an increase in energy used to control the temperature. The prototype showed a high performance during the hottest period when it is more important to limit high temperatures for better storage of agriculture and food products. In particular, the surveyed indoor temperature showed a constant trend in both monitored periods. This effect was due to PCM heat stabilization. The constant temperature trend is important to limit food and agricultural product waste and shorten the time during which the HVAC system is in use.

Similar studies highlighted that the PCM can be employed for excess temperature control and to reduce the amount of cooling energy used in houses (Ozdenefe and Dewsbury, 2016). Its growing application for food and agriculture product storage above all in agricultural farms could be an important way of supporting sustainable agriculture, the farm economic performance, and consumers who will eat safer and healthier products (Barreca and Cardinali, 2019).

\section{Conclusions}

The results showed the high efficiency of the container prototype designed. The PCM layers improve the energy performance of the container by about $30 \%$, although it is necessary to highlight the importance of the choice and use of the correct melting temperature of the PCM. In fact, an incorrect choice of the PCM melting temperature does not lead to energy savings and rather can sometimes increase the energy usage, as was shown by the results. In particular, the two layers of PCM allowed us to obtain a high energy saving for cooling, because the external PCM layer with a melting temperature of $25^{\circ} \mathrm{C}$ absorbed outdoor heat at the hottest time of day, releasing it into the environment, when the external temperature decreased. The internal PCM layer, which has a melting temperature close to $20^{\circ} \mathrm{C}$, stabilized the indoor temperature at around this value; therefore, the HVAC system used less electrical energy to condition the environment. A comparison between the simulated values, in particular of the energy usage, showed the high reliability of the simulation model developed using the Design builder and Energy plus software. It is important to note that the accuracy of the results is correlated with all the model parameters, which mainly depend on the accuracy of the material thermal characteristic values and the weather parameters. For these reasons, in this study it was fundamental to know the enthalpy function of the PCM layers used, which the manufacturer made available to us, and the out-

Table 5. Energy consumption measured to maintain a temperature of $17^{\circ} \mathrm{C}$ inside the prototype.

\begin{tabular}{lccc}
\hline Energy used by Prototype & October $[\mathrm{kWh}]$ & November [kWh] & Total \\
Measured & 45.71 & 17.34 & 63.05 \\
Model with PCM & 43.51 & 35.34 & 61.64 \\
\hline Model without PCM & 28.14 & 20.59 & 48.73 \\
\hline
\end{tabular}

PCM, phase change material. 
door thermal parameters surveyed during the prototype monitoring period. The prototype of the storage unit showed a high energy saving only during the hot season. Future research should be conducted to develop an HVAC split system for the storage unit, fed by a standalone photovoltaic panel system, that will make the storage unit a nearly zero-energy cool space.

\section{References}

Alawadhi E.M. 2008. Thermal analysis of a building brick containing phase change material. Energy Build. 40, 351-7.

Barbaresi A., Bovo M., Santolini E., Barbaresi L., Torreggiani D., Tassinari P. 2020a. Development of a low-cost movable hot box for a preliminary definition of the thermal conductance of building envelopes. Build. Environ. 180:107034.

Barbaresi A., Bovo M., Torreggiani D. 2020b. The dual influence of the envelope on the thermal performance of conditioned and unconditioned buildings. Sustain. Cities Soc. 61:102298.

Barbaresi A., Torreggiani D., Benni S., Tassinari P. 2014. Underground cellar thermal simulation: Definition of a method for modelling performance assessment based on experimental calibration. Energy Build. 76:363-72.

Barreca F., Cardinali G.D. 2019. ITACAFood: A model to certificate the sustainability of food processing facilities. Sustain. 11:174601.

Barreca F., Fichera C.R. 2016. Thermal insulation performance assessment of agglomerated cork boards. Wood Fiber Sci. 48.

Barreca F., Modica G., Di Fazio S., Tirella V., Tripodi R., Fichera C.R. 2017. Improving building energy modelling by applying advanced 3D surveying techniques on agri-food facilities. J. Agric. Eng. 48:203-8.

Barreca F., Praticò P. 2019. Environmental indoor thermal control of extra virgin olive oil storage room with phase change materials. J. Agricult. Engine. 50:947.

Barreca F., Praticò P. 2018. Post-occupancy evaluation of buildings for sustainable agri-food production - a method applied to an olive oil mill. Buildings 8:83.

Basinska M., Kaczorek D., Koczyk H. 2021. Economic and Energy Analysis of Building Retrofitting Using Internal Insulations. Energies 14:1-18.

Boussaba L., Foufa A., Makhlouf S., Lefebvre G., Royon L. 2018. Elaboration and properties of a composite bio-based PCM for an application in building envelopes. Constr. Build. Mater. 185:156-65.

Buonomano A., De Luca G., Montanaro U., Palombo A. 2016. Innovative technologies for NZEBs: An energy and economic analysis tool and a case study of a non-residential building for the Mediterranean climate. Energy Build. 121:318-43.

Canali M., Amani P., Aramyan L., Gheoldus M., Moates G., Östergren K., Silvennoinen K., Waldron K., Vittuari M. 2017. Food waste drivers in Europe, from identification to possible interventions. Sustain. 9:010037.

Caprara C., Stoppiello G. 2012. Heat storage system with phase change materials in cogeneration units: study of preliminary model. J. Agricult. Engine. 39:jae.2008.4.9.

Castell A., Medrano, M., Castellón, C., Cabeza, L.F., 2009. Analysis of the simulation models for the use of PCM in buildings. Effstock Therm. Energy Storage Effic. Sustain. 1-8.

Di Perna C., Stazi F., Casalena A.U., D’Orazio M. 2011. Influence of the internal inertia of the building envelope on summertime comfort in buildings with high internal heat loads. Energy Build. 43:200-6.

European Commission, 2019. The European Green Deal. Available from: https://ec.europa.eu/info/strategy/priorities-20192024/european-green-deal_en

Eurostat, 2021. Final energy consumption by sector. Available from: https://ec.europa.eu/eurostat/ databrowser/view/ten 00124/default/le?lang=en Accessed: 23 March 2021.

Gao E., Zhang B., Stephenson L.D., Boddu V., Trovillion J. 2013. Prediction of phase change material (PCM) degradation. Therm. Perform. Exter. Envel. Whole Build. - 12th Int. Conf.

Gourlis G., Kovacic I. 2016. Building information modelling for analysis of energy efficient industrial buildings - a case study. Renew. Sustain. Energy Rev. 1-11.

Haberl J.S., Claridge D.E., Culp C. 2005. ASHRAE's Guideline 14-2002 for measurement of energy and demand savings: how to determine what was really saved by the retrofit. pp 1-13 in Fifth Int. Conf. Enhanc. Build. Oper.

Jaffal I., Inard C. 2017. A metamodel for building energy performance. Energy Build. 151:501-10.

Ladha-Sabur A., Bakalis S., Fryer P.J., Lopez-Quiroga E. 2019. Mapping energy consumption in food manufacturing. Trends Food Sci. Technol. 86:270-80.

Osterman E., Tyagi V.V., Butala V., Rahim N.A., Stritih U. 2012. Review of PCM based cooling technologies for buildings. Energy Build. 49:37-49.

Ozdenefe M., Dewsbury J. 2016. Thermal performance of a typical residential Cyprus building with phase change materials. Build. Serv. Engine. Res. Technol. 37:85-102.

Özonur Y., Mazman M., Paksoy H.Ö., Evliya H. 2006. Microencapsulation of coco fatty acid mixture for thermal energy storage with phase change material. Int. J. Energy Res. 30:741-9.

Parlato M.C.M., Porto S.M.C. 2020. Organized framework of main possible applications of sheep wool fibers in building components. Sustain. 12:030761.

Pérez-Lombard L., Ortiz J., Coronel J.F., Maestre I.R. 2011. A review of HVAC systems requirements in building energy regulations. Energy Build. 43:255-68.

Porto S.M.C., Valenti F., Bella S., Russo A., Cascone G., Arcidiacono C. 2017. Improving the effectiveness of heat treatment for insect pest control in flour mills by thermal simulations. Biosyst. Eng. 164:189-99.

Rosso F., Peduzzi A., Diana L., Cascone S., Cecere C. 2021. A sustainable approach towards the retrofit of the public housing building stock: energy-architectural experimental and numerical analysis. Sustain. [Epub ahead of print].

Ruiz G.R., Bandera C.F. 2017. Validation of calibrated energy models: Common errors. Energies 10:10101587.

Sims R., Flammini A., Puri M., Bracco S. 2016. Opportunities for agri-food chains to become energy-smart. ISBN 978-92-5108959-0. Rome: Food and Agriculture Organization of the United Nations, and Washington DC: USAID

Sutterlin W.R. 2015. A phase change materials comparison: vegetable-based vs. paraffin-based PCMs. Chem. Online 1-5.

Talašová J., Holeček P. 2009. Multiple-criteria fuzzy evaluation: the fuzzme software package. pp 681-686 in 2009 Int. Fuzzy Syst. Assoc. World Congr. 2009 Eur. Soc. Fuzzy Log. Technol. Conf. IFSA-EUSFLAT 2009 - Proc.

Tinti F., Barbaresi A., Benni S., Torreggiani D., Bruno R., Tassinari P. 2015. Experimental analysis of thermal interaction between wine cellar and underground. Energy Build. 104:275-86.

Zastawna-Rumin A., Kisilewicz T., Berardi U. 2020. Novel simulation algorithm for modeling the hysteresis of phase change materials. Energies 13:1-15. 